\title{
Spontaneous Intracranial Hypotension: Atypical Radiologic Appearances, Imaging Mimickers, and Clinical Look-Alikes
}

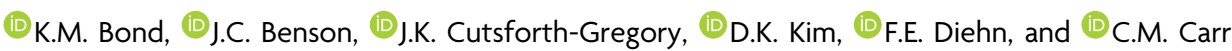

\begin{abstract}
SUMMARY: Spontaneous intracranial hypotension is a condition characterized by low CSF volume secondary to leakage through a dural defect with no identifiable cause. Patients classically present with orthostatic headaches, but this symptom is not specific to spontaneous intracranial hypotension, and initial misdiagnosis is common. The most prominent features of spontaneous intracranial hypotension on intracranial MR imaging include "brain sag" and diffuse pachymeningeal enhancement, but these characteristics can be seen in several other conditions. Understanding the clinical and imaging features of spontaneous intracranial hypotension and its mimickers will lead to more prompt and accurate diagnoses. Here we discuss conditions that mimic the radiologic and clinical presentation of spontaneous intracranial hypotension as well as other disorders that CSF leaks can imitate.
\end{abstract}

ABBREVIATIONS: IgG4 = immunoglobulin G4; POTS = postural orthostatic tachycardia syndrome; $\mathrm{SIH}=$ spontaneous intracranial hypotension; $\mathrm{SS}=$ superficial siderosis

$\mathbf{T}$ he clinical syndrome of orthostatic headache that resolves with recumbency or worsens with Valsalva maneuvers raises suspicion of low CSF pressure, most frequently due to a spinal CSF leak. These leaks may be from iatrogenic dural defects, such as lumbar punctures or drains (secondary intracranial hypotension). In contrast, spontaneous intracranial hypotension (SIH) or CSF hypovolemia refers to leaks that arise spontaneously. These terms can be misleading, however, because most patients have normal opening pressure. ${ }^{1}$ The term "spontaneous spinal CSF leak" may be a more accurate description of this condition, though we will continue to refer to it as SIH throughout this review.

SIH is estimated to affect 5 per 100,000 people per year, with predominance for women. ${ }^{2}$ It is thought to arise when mechanical stressors cause or exacerbate underlying weakness in the spinal dura, which may be exacerbated by connective tissue disease. Spiculated osteophytes, herniated discs, and nerve root diverticula can incite small dural tears that allow CSF to leak out of the thecal sac into the extradural space. ${ }^{2,3}$ CSF-venous fistulas can also allow leakage into the epidural space in the absence of a dural tear. $^{4,5}$

Received March 2, 2020; accepted after revision April 30.

From the Mayo Clinic School of Medicine (K.M.B.), Rochester, Minnesota; and Departments of Radiology (J.C.B., D.K.K., F.E.D., C.M.C.), and Neurology (J.K.C.-G.), Mayo Clinic, Rochester, Minnesota.

Please address correspondence to Carrie Carr, MD, Department of Radiology, Mayo Clinic, 200 First St SW, Rochester MN 55905; e-mail: carr.carrie@mayo.edu

-- Indicates open access to non-subscribers at www.ajnr.org

http://dx.doi.org/10.3174/ajnr.A6637
The most characteristic features of SIH on intracranial MR imaging include diffuse pachymeningeal enhancement and "brain sag," which, in a retrospective review of 99 cases, were seen in $83 \%$ and $61 \%$ of cases, resepectively. ${ }^{6}$ While some patients experience spontaneous resolution of symptoms, ${ }^{2}$ many will require more definitive treatment, including patching with blood or fibrin and surgical closure of the defect. ${ }^{7,8}$

As SIH has gained recognition within the medical community, particularly after the widespread adoption of MR imaging as a noninvasive diagnostic tool, patients with classic signs and symptoms have benefitted from earlier diagnosis and treatment., ${ }^{2,9}$ Many patients, however, present with vague neurologic symptoms such as nonpositional daily headache, cranial nerve palsy, gait disturbance, and cognitive dysfunction. Moreover, the source of the leak may remain occult despite advanced imaging in an estimated $46 \%-55 \%$ of patients. ${ }^{10}$ Further complicating matters, several conditions have imaging features that overlap SIH.

Understanding the clinical and imaging features of SIH and its mimickers will lead to more prompt and accurate diagnoses. Here we discuss conditions that mimic the radiologic and clinical presentation of SIH (Table 1), as well as other disorders that CSF leaks can imitate (Table 2). Nonspecific radiographic findings to be discussed include bilateral subdural fluid collections or hematomas and conditions with dural thickening. Conditions with some shared imaging features include Chiari type I malformations and diencephalic-mesencephalic junction dysplasia. Nonspecific clinical mimics include orthostatic headaches, cervicogenic headache, and vestibular migraine. Postural orthostatic tachycardia syndrome 


\begin{tabular}{|c|c|c|}
\hline & Distinguishing Features & SIH \\
\hline \multicolumn{3}{|l|}{ Radiologic mimickers } \\
\hline \multirow[t]{2}{*}{ Chiari type I malformation } & Cerebellar tonsils inferiorly pointed & Normal cerebellar tonsil shape \\
\hline & Midbrain descent absent & Midbrain descent present \\
\hline \multirow[t]{2}{*}{ Subdural fluid collections } & Usually unilateral & Usually bilateral \\
\hline & & Brain sag and focal dural enhancement \\
\hline \multirow{2}{*}{$\begin{array}{l}\text { Conditions with dural thickening (IgG4- } \\
\text { related disease, neurosarcoidosis, } \\
\text { tuberculosis, autoimmune diseases, } \\
\text { infectious diseases) }\end{array}$} & $\begin{array}{l}\text { Focal or diffuse } \\
\text { May have leptomeningeal involvement, skull base } \\
\text { prominence, hypertrophic pachymeningitis }\end{array}$ & $\begin{array}{l}\text { Diffuse, non-nodular dural thickening } \\
\text { and enhancement }\end{array}$ \\
\hline & $\begin{array}{l}\text { Usually systemic symptoms and involvement of } \\
\text { other organs }\end{array}$ & \\
\hline \multicolumn{3}{|l|}{ Clinical mimickers } \\
\hline POTS & $\begin{array}{l}\text { Increased heart rate with minimal change in blood } \\
\text { pressure on standing from a seated or supine } \\
\text { position }\end{array}$ & $\begin{array}{l}\text { Stable heart rate with postural } \\
\text { changes }\end{array}$ \\
\hline \multirow[t]{2}{*}{ Orthostatic hypotension } & $\begin{array}{l}\text { Autonomic failure, medication effect, } \\
\text { hypovolemia }\end{array}$ & $\begin{array}{l}\text { Stable blood pressure with postural } \\
\text { changes }\end{array}$ \\
\hline & $\begin{array}{l}\text { Fall in systolic }(20 \mathrm{~mm} \mathrm{Hg}) \text { and/or diastolic }(10 \mathrm{~mm} \\
\mathrm{Hg} \text { ) blood pressure on standing from a seated } \\
\text { or supine position }\end{array}$ & \\
\hline Cervicogenic headache & $\begin{array}{l}\text { Headache with neck pain that worsens with } \\
\text { cervical motion, relieved with medication }\end{array}$ & $\begin{array}{l}\text { Pain is typically centered in the head } \\
\text { and not worsened by cervical } \\
\text { motion or improved with } \\
\text { medications }\end{array}$ \\
\hline Vestibular migraine & $\begin{array}{l}\text { Vertigo, unilateral headache, nystagmus, presence } \\
\text { of aura, history of migraine }\end{array}$ & $\begin{array}{l}\text { Hearing changes and tinnitus more } \\
\text { than vertigo or nystagmus }\end{array}$ \\
\hline
\end{tabular}

Table 2: Conditions that occasionally coexist with spontaneous intracranial hypotension

\begin{tabular}{cc}
\hline Coexisting Condition & \multicolumn{1}{c}{ Pathogenesis } \\
$\begin{array}{c}\text { Cerebral venous sinus } \\
\text { thrombosis } \\
\begin{array}{c}\text { Frontotemporal } \\
\text { dementia }\end{array}\end{array}$ & $\begin{array}{c}\text { Compensatory venous engorgement and stasis secondary to } \\
\text { decrease in intracranial CSF volume } \\
\text { Brain sag, obstruction of venous outflow, and swelling of the } \\
\text { diencephalon may precipitate behavior and personality } \\
\text { changes } \\
\text { Pituitary enlargement } \\
\text { or apoplexy }\end{array}$ \\
$\begin{array}{c}\text { Compensatory enlargement and congestion of hypophyseal veins } \\
\text { may cause pituitary engorgement and predisposition to } \\
\text { apoplexy }\end{array}$ \\
Superficial siderosis & $\begin{array}{c}\text { Prolonged supine deconditioning secondary to spinal CSF leak } \\
\text { Venous traction at the skull base may cause microhemorrhages, } \\
\text { or bleeding may occur at the site of the dural defect }\end{array}$ \\
\hline
\end{tabular}

and enhancement. ${ }^{11}$ Other possible imaging features include ventricular collapse, dural venous sinus engorgement, atraumatic subdural hematomas or hygromas, and pituitary enlargement. Due to the effacement of the perichiasmatic cistern and pituitary engorgement, the optic chiasm can appear to be directly draped over the pituitary gland. Note that there is wide variability as to how many signs may or may not be present in a given patient. Dobrocky et $\mathrm{al}^{12}$ have proposed a scor-

(POTS) is an alternative diagnosis with shared symptoms. SIH may present as an alternate clinical entity with the leak ultimately found as the cause for the condition. These secondary conditions include cerebral venous sinus thrombosis, frontotemporal dementia, and superficial siderosis. Other entities that are associated with SIH include pituitary tumors and apoplexy.

\section{Radiologic Findings of SIH and Its Mimickers}

If SIH is suspected, brain MR imaging with and without gadolinium contrast enhancement is the initial imaging examination of choice. Brain sag, or the downward displacement of the cerebellar tonsils and brain stem, is a classic finding. ${ }^{9}$ Flattening of the ventral pons, effacement of the subarachnoid spaces including the prepontine and perichiasmatic cisterns, and descent of the iter (superior opening of the cerebral aqueduct) below the incisural line are additional manifestations of brain sag. With or without brain sag, many patients' scans will demonstrate diffuse, smooth dural thickening ing method to determine the likelihood of SIH (low, intermediate, or high) based on the presence of 6 of these MR imaging findings. Additionally, superficial siderosis may be present in situations in which there is chronic bleeding into the thecal sac, typically related to recurrent trauma from a spiculated osteophyte or disk protrusion. ${ }^{13}$ Even when brain MR imaging findings are normal, a few case reports have described radioisotope cisternography showing reduced tracer activity over the cerebral convexities 24 hours after tracer injection, thereby supporting the diagnosis of SIH. ${ }^{14-16}$

Approaches to spinal imaging in patients with suspected $\mathrm{SIH}$ vary widely among institutions. Either a spinal MR imaging or CT myelography may be performed to evaluate the presence of extradural fluid collections. A "fast" leak is suspected if such a collection is identified, often leading to the use of either a dynamic CT myelogram or a digital subtraction myelogram to localize the leak. ${ }^{9,16}$ Spine MR imaging may also demonstrate secondary/supportive findings of SIH such as dural thickening and enhancement or engorgement of the epidural venous plexus. ${ }^{17}$ 


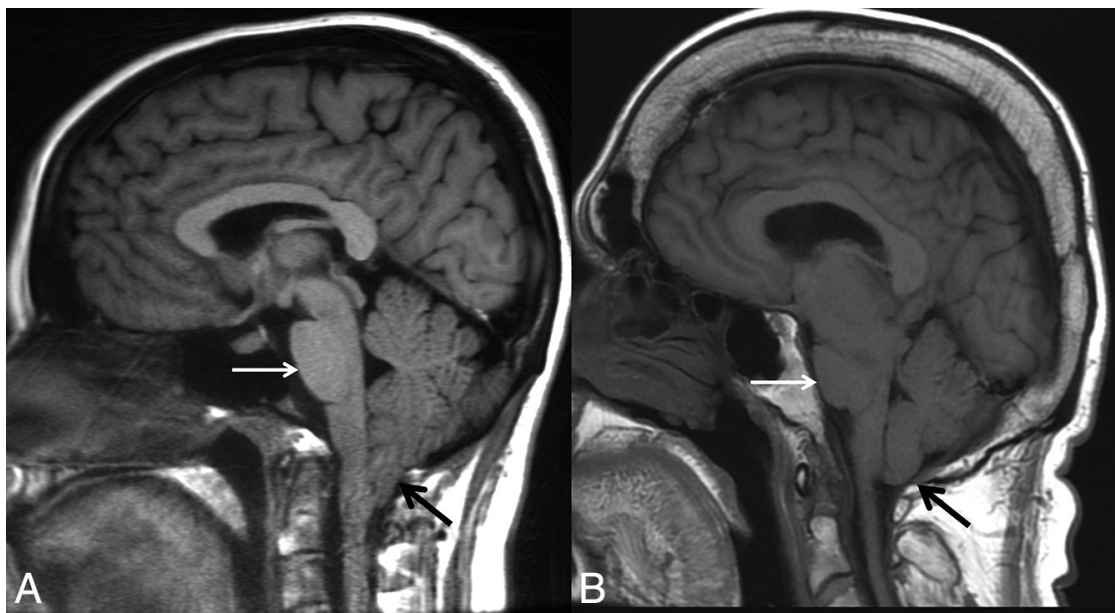

FIG 1. Chiari type I malformation versus SIH. A, Sagittal TIWI demonstrates a Chiari type I malformation with descent of cerebellar tonsils $1.4 \mathrm{~cm}$ below the foramen magnum (black arrow). Note the typical "peglike" morphology. The prepontine cistern is preserved, and the pons maintains a rounded ventral morphology (white arrow). B, Sagittal TIWI in a patient with severe brain sag due to SIH shows mild descent of the cerebellar tonsils at the foramen magnum (black arrow), but with normal morphology. The pons is flattened (white arrow) with effacement of the prepontine cistern. There is also profound effacement of the subarachnoid spaces in the posterior fossa.
SIH can be mistaken for a Chiari type I malformation on imaging (Fig 1) due to the superficially similar radiologic appearance of cerebellar tonsillar descent. ${ }^{9}$ Although in some cases the differentiation can be challenging, there are several key imaging differences. In SIH, the tonsils usually maintain their normal shape rather than being inferiorly pointed and often do not descend more than $5 \mathrm{~mm}$ below the foramen magnum. ${ }^{22,23}$ In addition, the midbrain also descends in SIH, whereas it will maintain a normal position in Chiari type I. The superior aspect of the cerebral aqueduct (iter) may fall beneath the incisural line, which extends from the anterior tuberculum sellae to the inferior point of the venous confluence of the straight sinus, whereas it does not change position in Chiari type I. ${ }^{24,25}$ The presence of a syrinx will generally

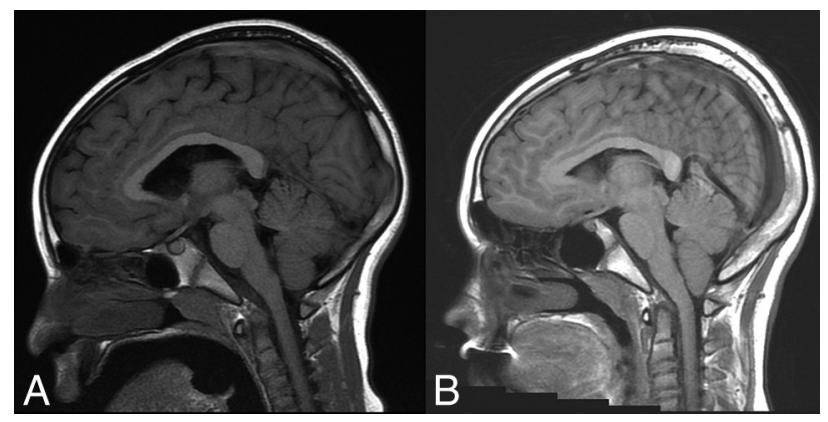

FIG 2. "Acquired" Chiari malformation showing findings of CSF hypotension. A, Sagittal TIWI demonstrates a normal appearance of the posterior fossa of a 6-year-old patient with a ventriculoperitoneal shunt. $B$, Six years later, imaging demonstrates findings of overshunting resulting in CSF hypotension. This has previously (mistakenly) been called "acquired Chiari malformation." In addition to descent of the tonsils, there is also effacement of the subarachnoid spaces, flattening of the pons, descent of the brain stem, and a decrease in the volume of the lateral and fourth ventricles, all of which indicate reduced CSF volume.

Nerve root sleeve diverticula are commonly seen, though these are nonspecific and of unclear significance unless they are very large and irregular. ${ }^{18}$

Chiari Type I Malformation. A Chiari type I malformation is an abnormal morphology at the craniocervical junction, classically defined as descent of the cerebellar tonsils at least $5 \mathrm{~mm}$ through the foramen magnum. The prevalence is estimated to be $<1 \%$ in the general population, and most of these patients are asymptomatic. ${ }^{19,20}$ Tonsillar descent can obstruct CSF outflow and thereby cause symptoms of cough-induced headache, paresthesia, lower cranial neuropathies, and cerebellar signs. ${ }^{21}$ Disruption of normal flow of the CSF can also result in syringomyelia. Treatment of symptomatic Chiari is by posterior fossa decompression. indicate a Chiari type I malformation, though there are rare reports of this developing in $\mathrm{SIH}^{26}$ The subarachnoid spaces in the posterior fossa, foramen magnum, and normal ventricular caliber will be preserved in Chiari I malformations, whereas they will be effaced in SIH. Flattening of the pons is commonly seen with pronounced SIH-associated brain sag but will not be present with Chiari type I malformations, in which the prepontine cistern will be maintained. Finally, patients with a Chiari malformation will not exhibit diffuse dural enhancement.

The literature describes multiple reports of "acquired" Chiari I malformations in the setting of spinal CSF drainage (eg, ventriculoperitoneal shunts). Images from these reports do show cerebellar descent, but many also show findings of intracranial hypotension. Overshunting, in which CSF diverted at a rate greater than production, results in an iatrogenic cause of intracranial hypotension or hypovolemia. The underlying physiology is similar to that of SIH (though iatrogenic in origin) and shares similar findings of slit-like ventricles, effacement of the subarachnoid spaces in the posterior fossa, flattening of the ventral pons, and descent of the brain stem and tonsils (Fig 2).

Subdural Fluid Collections or Hematomas. Subdural hematoma is a condition that disproportionately affects elderly patients and is often associated with minor head trauma. Bridging veins are predisposed to tear in this population because they cross the subarachnoid spaces, which expand as a function of age due to brain parenchymal atrophy. Anticoagulation is a factor in 5\%$20 \%$ of patients with chronic subdural hematomas. ${ }^{27,28}$ Subdural hygromas occur due to compensatory enlargement of the subdural/subarachnoid space secondary to the loss of the CSF volume. A subdural hematoma can also occur if there is tearing of abnormally engorged cortical veins. In a series of 98 patients with chronic subdural hematomas, $26 \%$ were found to be bilateral. ${ }^{29}$ Bilateral subdural collections have been known to occur in the 


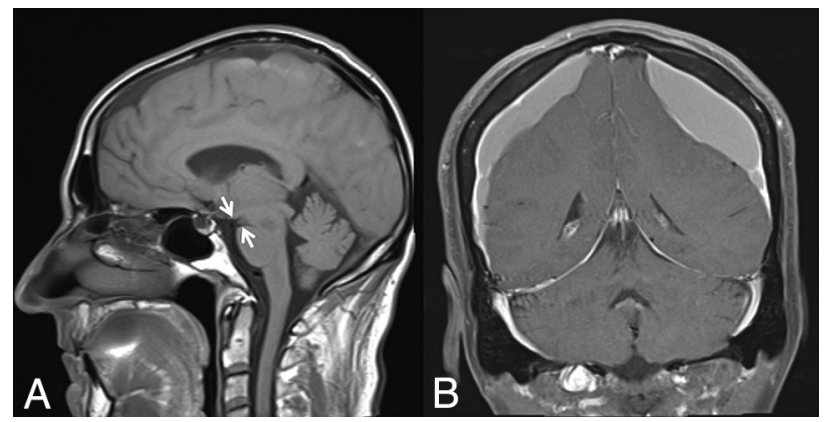

FIG 3. Bilateral subdural hematomas as an initial presentation in $\mathrm{SIH}$. $A$, Sagittal TIWI shows a subtle decrease in the mamillopontine distance (white arrow). Otherwise, the typical stigmata of $\mathrm{SIH}$ are not present. B, Coronal postcontrast TIWI demonstrates large bilateral subdural hematomas with mass effect on the cerebral hemispheres. A hyperdynamic CT myelogram showed a leak in the thoracic spine, and a targeted blood patch was performed. The subdural hematomas subsequently required evacuation due to cerebral compression. All of the patient's symptoms resolved, and the hematomas did not recur.

setting of SIH (Fig 3). ${ }^{29-31}$ These bilateral subdural collections can occur either with or without the characteristic intracranial stigmata of SIH (eg, brain sag and focal dural enhancement). The fluid collections may occur as only a hygroma or a subacute/ chronic hematoma. Unilateral occurrence is rare. It is imperative that the appropriate etiology be identified because subdural fluid collections will not resolve until there is successful treatment of the underlying SIH. If the collections are drained, they will recur due to the underlying abnormal CSF dynamics. ${ }^{32}$ Therapy should be focused on finding and treating the leak rather than drainage of the collections. With appropriate treatment, the collections will gradually resolve. ${ }^{33}$

Conditions with Dural Thickening. A key radiologic finding of $\mathrm{SIH}$ is dural thickening and enhancement, which are usually diffuse and non-nodular. Several rare conditions can have a similar appearance on MR imaging. Such hypertrophic pachymeningitis can have a specific etiology or be idiopathic. Immunoglobulin 4 (IgG4)-related disease, a known cause of pachymeningitis, is a fibroinflammatory condition caused by the infiltration of lymphoplasmacytic cells into tissues and subsequent fibrosis. ${ }^{34,35}$ It can manifest in nearly every organ system and, therefore, has a wide variety of presentations. The hypertrophic pachymeningitis due to IgG4-related disease can affect the dura intracranially or in the spinal canal. ${ }^{35}$ On MR imaging, the dura is thickened, enhances, and has a shortened T2 signal due to fibrotic changes (Fig 4). Neurosarcoidosis, another idiopathic systemic disease with variable clinical presentation, can cause pachymeningeal and/or leptomeningeal thickening and enhancement, which are generally most prominent along the skull base. ${ }^{36}$ In addition, lesions of the brain parenchyma, cranial and peripheral nerves, and bones are not unusual. ${ }^{37,38}$ Dural thickening can also occur secondary to a variety of noninfectious, non-neoplastic conditions (broadly including immune-mediated, histiocytic, granulomatous, and idiopathic), such as rheumatoid arthritis, ${ }^{39,40}$ temporal arteritis, ${ }^{41}$ Rosai-Dorfman disease, ${ }^{42,43}$ Erdheim-Chester disease, ${ }^{44}$ and polyangiitis with granulomatosis. ${ }^{45}$

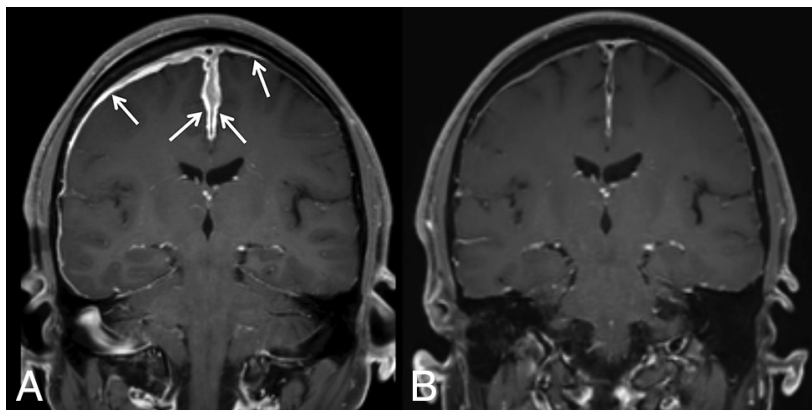

FIG 4. IgG4-related pachymeningitis. $A$, Coronal contrast-enhanced TIWI from a 53-year-old man with IgG4-related disease with Castleman-like features shows abnormal pachymeningeal enhancement (arrows). B, Follow-up imaging after steroid and rituximab (Rituxan) treatment demonstrates interval near resolution of the pachymeningeal enhancement.

Tuberculous meningitis is a severe manifestation of extrapulmonary tuberculosis with high associated mortality. ${ }^{46,47}$ Focal or diffuse dural thickening may be present on MR imaging, and the diagnosis is confirmed with biopsy. ${ }^{47}$ Tuberculosis can also affect the leptomeninges, form intracranial tuberculomas, and cause spinal tuberculous arachnoiditis. ${ }^{48,49}$ Other infectious causes of hypertrophic pachymeningitis include syphilis, Cryptococcus, and Lyme disease. ${ }^{50-52}$ Each of the conditions discussed here has the potential to affect multiple organ systems, and patients' clinical presentations often reflect involvement beyond the nervous system.

SIH should not be included in the differential if focal or nodular dural thickening is present because neoplastic or infectious etiologies would be the primary differential consideration. An operation or lumbar punctures may also show diffuse smooth dural enhancement similar to what is seen in SIH; however, correlation with relevant history will distinguish these entities.

\section{Clinical Mimics of SIH}

As the recognized clinical phenotype of spontaneous spinal CSF leak has broadened, so too has the differential diagnosis of the many signs and symptoms associated with this entity broadened. Several atypical presentations of bona fide SIH are discussed in the next section. Here we will focus on mimics of the most common symptom of SIH, orthostatic headache. Indeed, we have encountered patients with orthostatic headache due to a variety of causes other than spinal CSF leak, most often an autonomic disorder or an alternative secondary headache disorder.

POTS. POTS is perhaps the most common nonleak cause of headache that is triggered or worsened with upright posture. At least $25 \%$ of patients with POTS report headaches, and by definition, all have orthostatic worsening of symptoms. ${ }^{53}$ POTS is a diverse syndrome due to various etiologies, among which may occasionally be spinal CSF leakage. ${ }^{54}$ Some patients likely develop POTS secondary to the prolonged supine deconditioning that often occurs in the setting of a spinal CSF leak. There are also patients with POTS and orthostatic headaches in the absence of any evidence of CSF leakage. ${ }^{55}$ Complicating matters further, POTS 


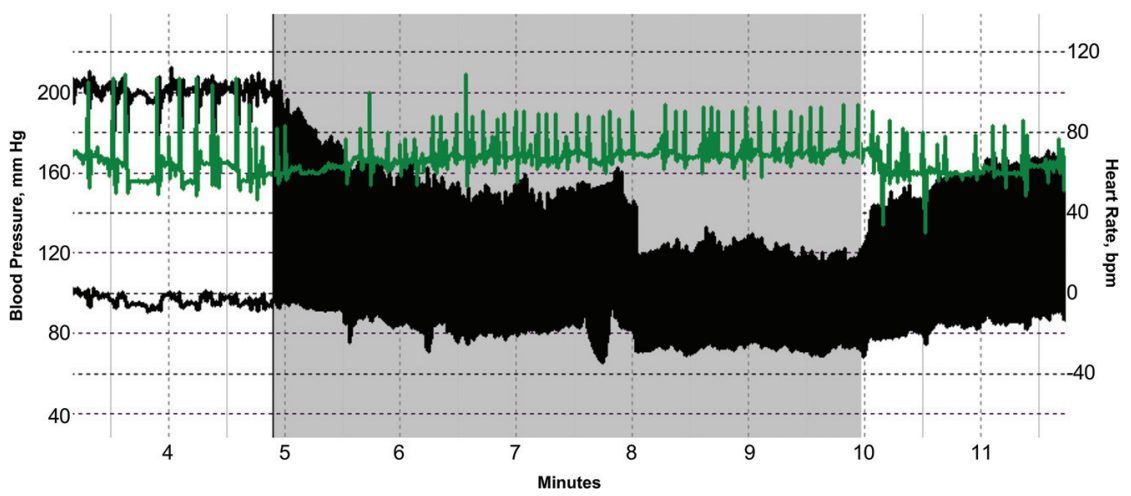

FIG 5. Autonomic failure presenting as orthostatic headache. Beat-to-beat blood pressure (black) and heart rate (green) of an 80-year-old woman during a tilt-table test show a sustained drop in blood pressure during head-up tilt (gray shading). The lack of heart rate acceleration suggests neurogenic orthostatic hypotension. When her mean blood pressure fell below $85 \mathrm{~mm} \mathrm{Hg}$, she developed posterior head and neck tightness (coat hanger pain) and lightheadedness. Thus, pure autonomic failure was initially misdiagnosed as orthostatic headache.

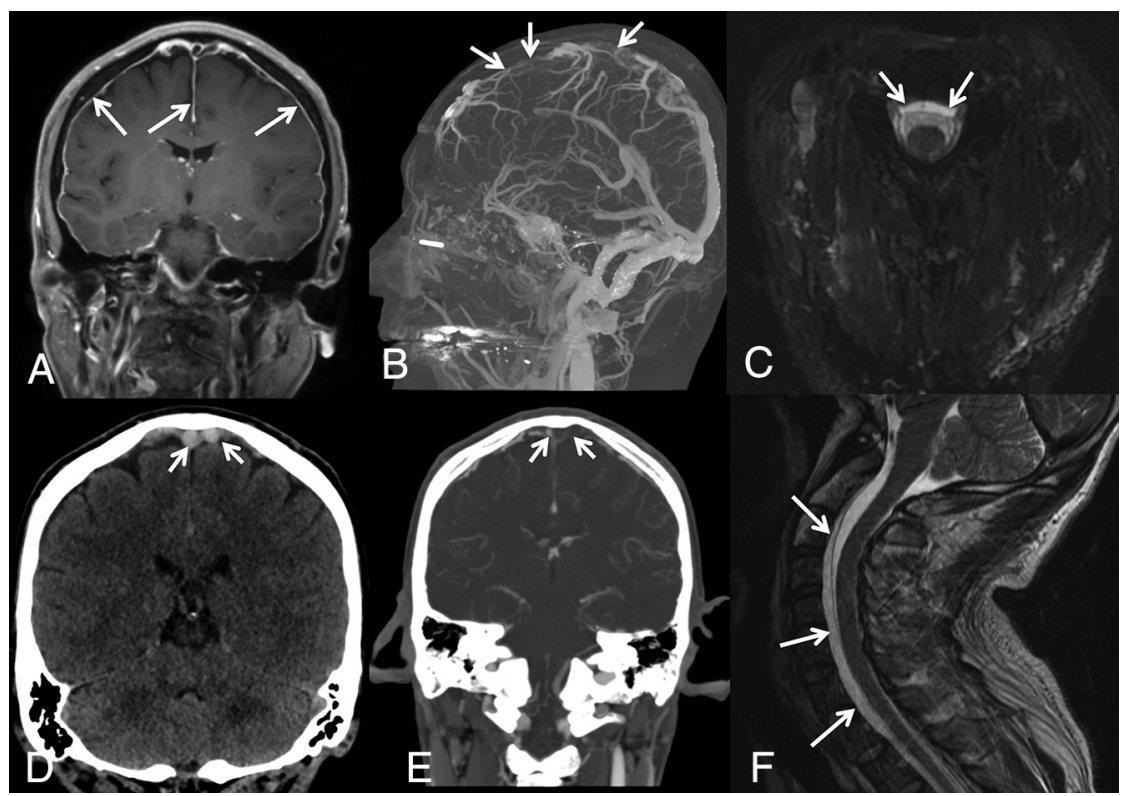

FIG 6. SIH presenting with venous sinus thrombosis. A 43-year-old man presented with sudden onset of headaches, dizziness, and nausea clinically suspected to represent migraines. A, Contrast-enhanced Tl-weighted image demonstrates diffuse, smooth, nonspecific thin pachymeningeal enhancement (arrows). The patient presented to the emergency department 3 days later with a marked increase in his headache and sudden onset of right lower-extremity weakness. $D$, Unenhanced coronal head CT demonstrates high attenuation and expansile content within the superior sagittal sinus and adjacent cortical veins, compatible with acute dural venous sinus and cortical vein thrombosis (selected clot highlighted by arrows). Sagittal MIP (B) and coronal $(E)$ images from a contrast-enhanced CT venogram confirm a long-segment acute, expansile thrombus as a filling defect within the superior sagittal sinus, as well as multiple bilateral left-greaterthan-right superior cortical veins (arrows). While he was being treated for sinus thrombosis, he reported that his headaches were orthostatic in nature. His condition continued to deteriorate with progression of the thrombosis despite treatment and parenchymal hemorrhage. Axial $(C)$ and sagittal $(F)$ T2WI demonstrates a ventral extradural fluid collection. A hyperdynamic CT myelogram was performed, and a leak was found at a spiculated osteophyte at T1-2.

shares risk factors with spinal CSF leak, including joint hypermobility and underlying disorders of the connective tissue matrix such as Ehlers-Danlos syndrome. ${ }^{53}$ POTS with or without spinal CSF leak should be considered when evaluating a patient with orthostatic headache. Measurement of the sitting and standing heart rate and blood pressure is, in our opinion, a reasonable screen for this diagnosis; patients with POTS demonstrate a rapid increase in heart rate and relatively stable blood pressure on standing. ${ }^{56}$

Orthostatic Hypotension. Orthostatic hypotension, which can be caused by autonomic failure (Fig 5), medication effect, or serious hypovolemia but not spinal CSF leakage, is another reasonably common cause of orthostatic headache. Whereas spinal CSF leakassociated headache is typically centered in the head, its focus in the occipital region and the frequent accompanying neck and back pain may be confused with the "coat hanger" pain in the neck and shoulders that results from paraspinal muscle ischemia in patients with orthostatic hypotension. ${ }^{57}$ Other symptoms that may occur with either spinal CSF leak or orthostatic hypotension include tinnitus, distorted hearing, fatigue, and worsening headache with Valsalva maneuvers. Similar to POTS, measurement of orthostatic vital signs should distinguish patients with orthostatic hypotension from those with suspected spinal CSF leak. Patients with orthostatic hypotension have a fall in systolic and/or diastolic blood pressure of $20 \mathrm{~mm} \mathrm{Hg}$ and $10 \mathrm{~mm} \mathrm{Hg}$, respectively, during a lying-to-standing, lying-to-sitting, or the head-up tilt test. ${ }^{58}$

Other Headache Disorders. Patients with cervicogenic headache or vestibular migraine will typically have worsening headache when attaining an upright position, which may raise suspicion of a spinal CSF leak. Cervicogenic headache results from a disorder or lesion of the bony cervical spine or soft tissues of the neck and is usually accompanied by neck pain. ${ }^{59}$ Most commonly, the offending pathology is osteoarthritis of the upper cervical spine or the atlantooccipital junction. ${ }^{59}$ The clinical symptoms are typically distinct from those of SIH: Cervicogenic headaches are usually unilateral and are accompanied by neck pain that is worsened during neck movement. ${ }^{59}$ Most important, they are also relieved by 
pharmaceutical blockade (ie, steroid injection) of the inciting cervical structure. ${ }^{59}$

Vestibular migraine shares many features with classic migraine (eg, unilateral location, pulsating quality, photophobia, phonophobia, visual aura) but is distinguished by the presence of head motion-induced, visually-induced, spontaneous, or positional vertigo. ${ }^{59}$ It is this postural worsening that introduces possible confusion with spinal CSF leak. Often, the migrainous features of the headache, as well as a history of documented migraines, may help distinguish vestibular migraine from SIH. In addition, nystagmus is often present and usually lasts as long as the precipitating head position is held. ${ }^{60}$

Finally, we have encountered at least 2 patients with headaches that were exclusively or largely orthostatic and developed after otherwise successful surgical decompression of bona fide Chiari type I malformation, despite no evidence of a postoperative CSF leak. The mechanism of these headaches was hypothesized to be sensitization of mechanosensitive dural nociceptors from altered skull-dura apposition. ${ }^{61}$ POTS, orthostatic hypotension, cervicogenic headache, vestibular migraine, and prior Chiari decompression surgery are all causes of orthostatic headache that may mimic spinal CSF leak and must be distinguished for patients to receive appropriately directed therapy.

\section{CSF Leak Presenting as a Different Disorder}

Cerebral Venous Sinus Thrombosis. While cerebral venous sinus thrombosis affects only about 4 per 1 million people in the general population, the prevalence is about $2 \%$ in patients with $\mathrm{SIH}^{62-65}$ There are several reasons why cerebral venous sinus thrombosis may be more prevalent in this population. As the volume of intracranial CSF decreases, compensation by the arterial and venous compartments must occur. Since veins are much more distensible than arteries, venous engorgement is common. ${ }^{66,67}$ Blood flows more slowly through veins of larger diameter, and this stasis increases coagulability. ${ }^{68}$ Furthermore, the characteristic brain sag of SIH can put tension on venous outflow tracts, thereby worsening venous expansion. ${ }^{62,67}$ In combination, these changes can provide an environment for thrombus formation within the venous sinuses (Fig 6). In patients with SIH, superimposed cerebral venous sinus thrombosis should be considered when there is a change in headache quality (from predictable and positional to severe and unrelenting) or new neurologic deficits develop. ${ }^{62,67,69-72}$ Similarly, patients with unprovoked cerebral venous sinus thrombosis should be assessed for possible underlying SIH.

Frontotemporal Dementia. Behavioral-variant frontotemporal dementia is characterized by disproportionate atrophy of the frontal and temporal lobes and classically has an early age of onset (younger than 60 years of age). ${ }^{73,74}$ Patients present with insidious personality changes, poor judgment, disinhibition, and apathy. Patients with SIH can also have behavioral changes, and there have been several reports of SIH presenting with frontotemporal dementia-like symptoms. ${ }^{75-78}$ The etiology of this relationship is not known but may be related to brain sag, obstruction of the venous outflow, and associated swelling of the diencephalon. ${ }^{78}$ In most cases, cognitive symptoms promptly improve almost immediately after treating the underlying $\mathrm{SIH}^{75-78}$

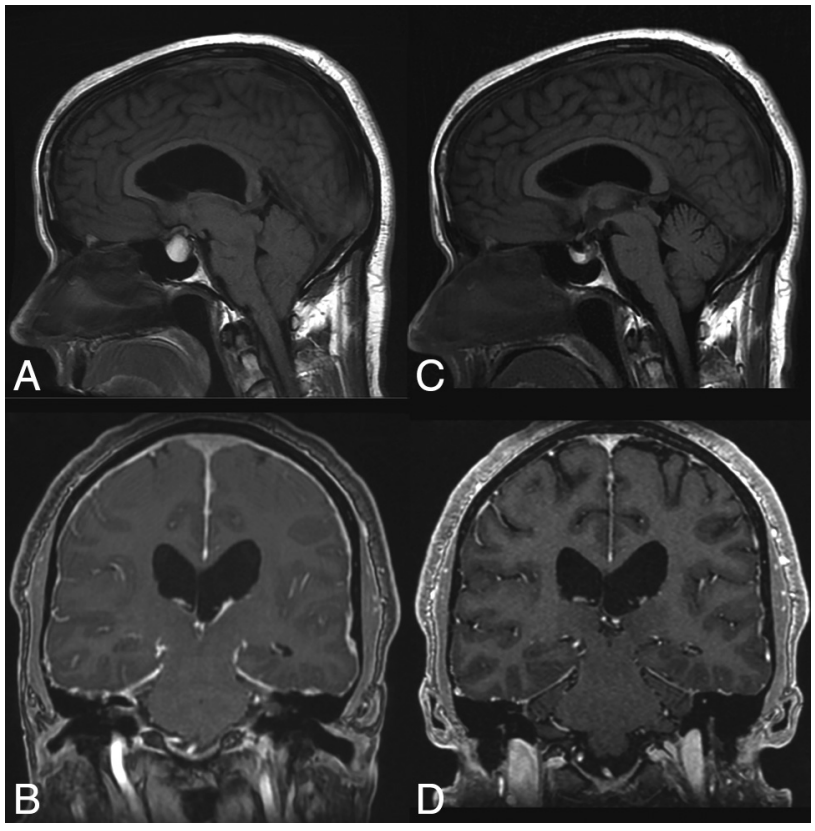

FIG 7. SIH presenting as pituitary apoplexy. Sagittal TIWI (A) and coronal postcontrast TTWI (B) images demonstrate a hyperintense lesion filling the sella and extending into the suprasellar cistern. The patient was diagnosed with pituitary apoplexy of a macroadenoma or a Rathke cleft cyst and a Chiari I malformation. However, the MR imaging actually demonstrates the expected intracranial stigmata of an $\mathrm{SIH}$, including severe brain sag and dural enhancement. Despite extensive evaluation, the source of the leak was not found. The patient was treated with a nontargeted blood patch. His headaches and imaging findings ( $C$ and $D$ ) resolved.

Pituitary Tumor or Apoplexy. As the volume of intracranial CSF declines in SIH, the compensatory enlargement of the cerebral venous system includes the hypophyseal veins. Thus, many patients with SIH have pituitary engorgement and upward bowing of the diaphragm sellae. ${ }^{79-81}$ These findings may lead to misdiagnosis as a nonfunctioning pituitary adenoma (Fig 7). ${ }^{82,83}$ Furthermore, due to the uniquely dense hypophyseal portal system, venous congestion can predispose patients to apoplexy, a rare-but-emergent hemorrhage, or infarction of the pituitary gland. SIH-induced pituitary engorgement may also suppress dopamine release and thereby raise prolactin levels. Galactorrhea only occasionally results.

Superficial Siderosis. Superficial siderosis (SS) is a radiologic or pathologic diagnosis of hemosiderin deposition in the leptomeninges and subpial layer of the central nervous system. About half of the cases are attributed to idiopathic chronic subarachnoid hemorrhage, and the other half have a known cause such as trauma, tumor, or arteriovenous malformation. ${ }^{84}$ Classically, SS occurs infratentorially, and patients present with ataxia, pyramidal signs, or sensorineural hearing loss. ${ }^{13,84,85}$ Supratentorial bleeding can occur, and this is referred to as cortical superficial siderosis. ${ }^{86}$

There have been several reports of SIH presenting with or coinciding with the presence of SS (Fig 8). ${ }^{87-89}$ One review of patients with SS noted a spinal extradural fluid collection in approximately $50 \%$ of patients. ${ }^{13}$ While SS is not reversible, repair of the inciting dural defect, often found via a dynamic CT myelogram, may prevent further bleeding and lead to stability or improvement of symptoms. ${ }^{90,91}$ 


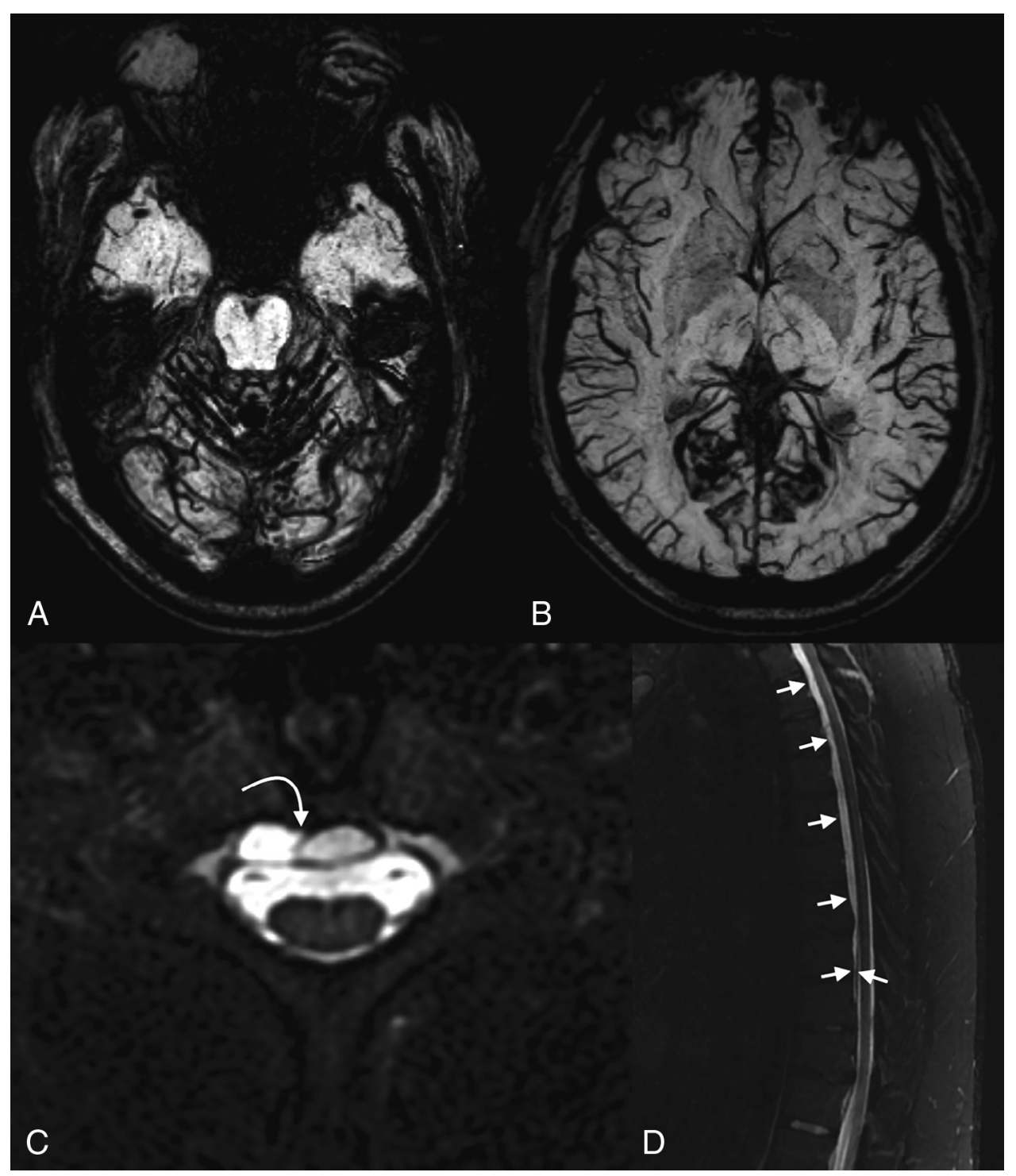

FIG 8. SIH presenting as superficial siderosis. A 37-year-old man who presented with episodes of dizziness and loss of consciousness was found to have diffuse posterior fossa-predominant superficial siderosis on axial SWI ( $A$ and $B)$. Subsequent imaging of the spine demonstrated a ventral extradural fluid collection (curved arrow, C; straight arrows, D). A subsequent hyperdynamic CT myelogram identified the source of the CSF leak, which was surgically repaired.

The etiologic mechanism that ties SS to SIH is uncertain. Some authors have suggested that the pathogenesis of SS is related to traction of the cerebellum and/or vermian veins on the skull base, leading to microhemorrhages and hemosiderin deposition. ${ }^{88}$ Others, noting the association between extradural spinal fluid collections and SS, have suggested that bleeding may occur at the site of the dural defect. ${ }^{92}$ The latter hypothesis has been supported by recent case reports of patients with hemorrhage within either the extradural fluid collection or thecal sac. ${ }^{93}$

\section{CONCLUSIONS}

Spontaneous intracranial hypotension is caused by various types of defects in the spinal dura and subsequent CSF extravasation. Patients classically present with orthostatic headache, low or normal CSF opening pressure on lumbar puncture, and brain sag with diffuse pachymeningeal enhancement on MR imaging. Many radiologic and clinical findings may mimic these classic findings, and conversely, secondary changes from SIH can give rise to symptoms that imitate other conditions. Because SIH is a curable condition, it is important for physicians to recognize its nonclassic presentations and be familiar with the differential diagnoses of its radiologic and clinical findings.

\section{ACKNOWLEDGMENTS}

The authors acknowledge the assistance of Sonia Watson, $\mathrm{PhD}$, in editing the manuscript.

Disclosures: Jeremy K. Cutsforth-Gregory—UNRELATED: Royalties: Oxford University Press, Comments: Mayo Clinic Medical Neurosciences (textbook).

\section{REFERENCES}

1. Kranz PG, Gray L, Amrhein TJ. Spontaneous intracranial hypotension: 10 myths and misperceptions. Headache 2018;58:948-59 CrossRef Medline

2. Schievink WI. Spontaneous spinal cerebrospinal fluid leaks and intracranial hypotension. JAMA 2006;295:2286-96 CrossRef Medline

3. Schievink WI, Meyer FB, Atkinson JL, et al. Spontaneous spinal cerebrospinal fluid leaks and intracranial hypotension. J Neurosurg 1996;84:598-60 CrossRef Medline 
4. Kranz PG, Amrhein TJ, Gray L. CSF venous fistulas in spontaneous intracranial hypotension: imaging characteristics on dynamic and CT myelography. AJR Am J Roentgenol 2017;209:1360-66 CrossRef Medline

5. Schievink WI, Moser FG, Maya MM. CSF-venous fistula in spontaneous intracranial hypotension. Neurology 2014;83:472-73 CrossRef Medline

6. Kranz PG, Tanpitukpongse TP, Choudhury KR, et al. Imaging signs in spontaneous intracranial hypotension: prevalence and relationship to CSF pressure. AJNR Am J Neuroradiol 2016;37:1374-78 CrossRef Medline

7. Sencakova D, Mokri B, McClelland RL. The efficacy of epidural blood patch in spontaneous CSF leaks. Neurology 2001;57:1921-23 CrossRef Medline

8. Schievink WI. A novel technique for treatment of intractable spontaneous intracranial hypotension: lumbar dural reduction surgery. Headache 2009;49:1047-51 CrossRef Medline

9. Schievink WI. Misdiagnosis of spontaneous intracranial hypotension. Arch Neurol 2003;60:1713-18 CrossRef Medline

10. Kranz PG, Amrhein TJ, Schievink WI, et al. The "hyperdense paraspinal vein" sign: a marker of CSF-venous fistula. AJNR Am J Neuroradiol 2016;37:1379-81 CrossRef Medline

11. Mokri B, Piepgras DG, Miller GM. Syndrome of orthostatic headaches and diffuse pachymeningeal gadolinium enhancement. Mayo Clin Proc 1997;72:400-13 CrossRef Medline

12. Dobrocky T, Grunder L, Breiding PS, et al. Assessing spinal cerebrospinal fluid leaks in spontaneous intracranial hypotension with a scoring system based on brain magnetic resonance imaging findings. JAMA Neurol 2019;76:580-87 CrossRef Medline

13. Kumar N, Cohen-Gadol AA, Wright RA, et al. Superficial siderosis. Neurology 2006;66:1144-52 CrossRef Medline

14. Spelle L, Boulin A, Pierot L, et al. Spontaneous intracranial hypotension: MRI and radionuclide cisternography findings. J Neurol Neurosurg Psychiatry 1997;62:291-92 CrossRef Medline

15. Sehgal AK, Sethi RS, Raghavan S, et al. Radionuclide cisternography: a prudent investigation in diagnosing spontaneous intracranial hypotension. Indian J Nucl Med 2013;28:42-44 CrossRef Medline

16. Yoo HM, Kim SJ, Choi CG, et al. Detection of CSF leak in spinal CSF leak syndrome using MR myelography: correlation with radioisotope cisternography. AJNR Am J Neuroradiol 2008;29:649-54 CrossRef Medline

17. Watanabe A, Horikoshi T, Uchida M, et al. Diagnostic value of spinal MR imaging in spontaneous intracranial hypotension syndrome. AJNR Am J Neuroradiol 2009;30:147-51 CrossRef Medline

18. Kranz PG, Stinnett SS, Huang KT, et al. Spinal meningeal diverticula in spontaneous intracranial hypotension: analysis of prevalence and myelographic appearance. AJNR Am J Neuroradiol 2013;34: 1284-89 CrossRef Medline

19. Meadows J, Kraut M, Guarnieri M, et al. Asymptomatic Chiari type I malformations identified on magnetic resonance imaging. $J$ Neurosurg 2000;92:920-26 CrossRef Medline

20. Morris Z, Whiteley WN, Longstreth WT, Jr, et al. Incidental findings on brain magnetic resonance imaging: systematic review and meta-analysis. BMJ 2009;339:b3016-16 CrossRef Medline

21. Langridge $B$, Phillips E, Choi D. Chiari malformation type 1: a systematic review of natural history and conservative management. World Neurosurg 2017;104:213-19 CrossRef Medline

22. Atkinson JL, Weinshenker BG, Miller GM, et al. Acquired Chiari I malformation secondary to spontaneous spinal cerebrospinal fluid leakage and chronic intracranial hypotension syndrome in seven cases. J Neurosurg 1998;88:237-42 CrossRef Medline

23. Holbrook J, Saindane AM. Imaging of intracranial pressure disorders. Neurosurgery 2017;80:341-54 CrossRef Medline

24. Sainani NI, Lawande MA, Pungavkar SA, et al. Spontaneous intracranial hypotension: a study of six cases with MR findings and literature review. Australas Radiol 2006;50:419-23 CrossRef Medline

25. Wald JT, Diehn FE. Spontaneous intracranial hypotension. Applied Radiol 2018;47:18-22
26. Smith RM, Garza I, Robertson CE. Chronic CSF leak causing syringomyelia and pseudo-Arnold-Chiari malformation. Neurology 2015;85:1994 CrossRef Medline

27. Luxon LM, Harrison MJ. Chronic subdural haematoma. Q J Med 1979;48:43-53 Medline

28. Schievink WI, Maya MM, Pikul BK, et al. Spontaneous spinal cerebrospinal fluid leaks as the cause of subdural hematomas in elderly patients on anticoagulation: report of 3 cases. J Neurosurg 2010; 112:295-99 CrossRef Medline

29. Huang YH, Yang KY, Lee TC, et al. Bilateral chronic subdural hematoma: what is the clinical significance? Int J Surg 2013;11:544-48 CrossRef Medline

30. Schievink WI, Maya MM, Moser FG, et al. Spectrum of subdural fluid collections in spontaneous intracranial hypotension. J Neurosurg 2005;103:608-13 CrossRef Medline

31. de Noronha RJ, Sharrack B, Hadjivassiliou M, et al. Subdural haematoma: a potentially serious consequence of spontaneous intracranial hypotension. J Neurol Neurosurg Psychiatry 2003;74:752-55 CrossRef Medline

32. Chen YC, Wang YF, Li JY, et al. Treatment and prognosis of subdural hematoma in patients with spontaneous intracranial hypotension. Cephalalgia 2016;36:225-31 CrossRef Medline

33. Rettenmaier LA, Park BJ, Holland MT, et al. Value of targeted epidural blood patch and management of subdural hematoma in spontaneous intracranial hypotension: case report and review of the literature. World Neurosurg 2017;97:27-38 CrossRef Medline

34. Stone JH, Zen Y, Deshpande V. IgG4-related disease. N Engl J Med 2012;366:539-51 CrossRef Medline

35. Lu LX, Della-Torre E, Stone JH, et al. IgG4-related hypertrophic pachymeningitis: clinical features, diagnostic criteria, and treatment. JAMA Neurol 2014;71:785-93 CrossRef Medline

36. Smith JK, Matheus MG, Castillo M. Imaging manifestations of neurosarcoidosis. AJR Am J Roentgenol 2004;182:289-95 CrossRef Medline

37. Pickuth D, Spielmann RP, Heywang-Köbrunner SH. Role of radiology in the diagnosis of neurosarcoidosis. Eur Radiol 2000;10:94144 CrossRef Medline

38. Zajicek JP, Scolding NJ, Foster O, et al. Central nervous system sarcoidosis: diagnosis and management. QJM 1999;92:103-17 CrossRef Medline

39. Otsuka M, Fujiwara T, Kuwata Y, et al. A case of rheumatoid pachymeningitis [in Japanese]. Rinsho Shinkeigaku 1997;37:834-40 Medline

40. Micheli F, Scorticati MC, Pikielny R, et al. Pachymeningeal thickening in rheumatoid arthritis. Eur Neurol 1993;33:397-98 CrossRef Medline

41. Marano E, D'Armiento FP, Scarano V, et al. Focal hypertrophic cranial pachymeningitis associated with temporal arteritis: a new case report. J Neurol 2003;250:98-100 CrossRef Medline

42. Wen JH, Wang C, Jin YY, et al. Radiological and clinical findings of isolated meningeal Rosai-Dorfman disease of the central nervous system. Medicine (Baltimore) 2019;98:e15365 CrossRef Medline

43. Z'Graggen WJ, Sturzenegger M, Mariani L, et al. Isolated RosaiDorfman disease of intracranial meninges. Pathol Res Pract 2006, 202:165-70 CrossRef Medline

44. Kumar P, Singh A, Gamanagatti S, et al. Imaging findings in Erdheim-Chester disease: what every radiologist needs to know. Pol J Radiol 2018;83:E54-62 CrossRef Medline

45. Parks NE, Goyal G, Go RS, et al. Neuroradiologic manifestations of Erdheim-Chester disease. Neurol Clin Pract 2018;8:15-20 CrossRef Medline

46. Chin JH. Tuberculous meningitis: diagnostic and therapeutic challenges. Neurol Clin Pract 2014;4:199-205 CrossRef Medline

47. Thurtell MJ, Keed AB, Yan M, et al. Tuberculous cranial pachymeningitis. Neurology 2007;68:298-300 CrossRef Medline

48. Fonseka CL, Kanakkahewa TE, Singhapura S, et al. Tuberculous pachymeningitis presenting as a diffused dural thickening in a patient with chronic headache and recurrent neurological abnormalities for more than a decade: a case report and a review of the literature. Case Rep Infect Dis 2018;2018:3012034 CrossRef Medline 
49. Goyal M, Sharma A, Mishra NK, et al. Imaging appearance of pachymeningeal tuberculosis. AJR Am J Roentgenol 1997;169:142124 CrossRef Medline

50. Blazekovic A, Ozretic D, Habek M, et al. Neurosyphilis: the shape of a rising threat. Int J Infect Dis 2018;76:1-3 CrossRef Medline

51. Rosa M Jr, de Almeida Cacador T, Biasutti C, et al. Teaching NeuroImages: skull and dural lesions in neurosyphilis. Neurology 2016;87: e129-30 CrossRef Medline

52. Mekinian A, Maisonobe L, Boukari L, et al. Characteristics, outcome and treatments with cranial pachymeningitis: a multicenter French retrospective study of 60 patients. Medicine (Baltimore) 2018;97:e11413 CrossRef Medline

53. Cutsforth-Gregory JK, Sandroni P. Clinical neurophysiology of postural tachycardia syndrome. Handb Clin Neurol 2019;161:429-45 CrossRef Medline

54. Graf N, Fernandes Santos AM, Ulrich CT, et al. Clinical symptoms and results of autonomic function testing overlap in spontaneous intracranial hypotension and postural tachycardia syndrome. Cephalalgia Reports 2018;1:251581631877377 CrossRef

55. Mokri B, Low PA. Orthostatic headaches without CSF leak in postural tachycardia syndrome. Neurology 2003;61:980-82 CrossRef Medline

56. Raj SR. The postural tachycardia syndrome (POTS): pathophysiology, diagnosis and management. Indian Pacing Electrophysiol $J$ 2006;6:84-99 Medline

57. Bleasdale-Barr KM, Mathias CJ. Neck and other muscle pains in autonomic failure: their association with orthostatic hypotension. $J R$ Soc Med 1998;91:355-59 CrossRef Medline

58. Naschitz JE, Rosner I. Orthostatic hypotension: framework of the syndrome. Postgrad Med J 2007;83:568-74 CrossRef Medline

59. Headache Classification Committee of the International Headache Society (IHS) The International Classification of Headache Disorders, 3rd edition. Cephalalgia 2018; 38:1-211 CrossRef Medline

60. Furman JM, Marcus DA, Balaban CD. Vestibular migraine: clinical aspects and pathophysiology. Lancet Neurol 2013;12:706-15 CrossRef Medline

61. Montenegro MM, Cutsforth-Gregory JK. Orthostatic headache after suboccipital craniectomy without CSF leak: two case reports. Headache 2018;58:1238-43 CrossRef Medline

62. Schievink WI, Maya MM. Cerebral venous thrombosis in spontaneous intracranial hypotension. Headache 2008;48:1511-19 CrossRef Medline

63. Stam J. Thrombosis of the cerebral veins and sinuses. N Engl J Med 2005;352:1791-98 CrossRef Medline

64. Zhang D, Wang J, Zhang Q, et al. Cerebral venous thrombosis in spontaneous intracranial hypotension: a report on 4 cases and a review of the literature. Headache 2018;58:1244-55 CrossRef Medline

65. Kataoka H, Tanizawa E, Ueno S. Spontaneous intracranial hypotension is associated with a risk of venous sinus thrombosis and subdural hematoma. Cerebrovasc Dis 2007;23:315-17 CrossRef Medline

66. Mokri B. The Monro-Kellie hypothesis: applications in CSF volume depletion. Neurology 2001;56:1746-48 CrossRef Medline

67. Rice CM, Renowden SA, Sandeman DR, et al. Spontaneous intracranial hypotension and venous sinus thrombosis. Pract Neurol 2013; 13:120-24 CrossRef Medline

68. Yoon KW, Cho MK, Kim YJ, et al. Sinus thrombosis in a patient with intracranial hypotension: a suggested hypothesis of venous stasis. A case report. Interv Neuroradiol 2011;17:248-51 CrossRef Medline

69. Costa P, Del Zotto E, Giossi A, et al. Headache due to spontaneous intracranial hypotension and subsequent cerebral vein thrombosis. Headache 2012;52:1592-96 CrossRef Medline

70. Savoiardo M, Armenise S, Spagnolo P, et al. Dural sinus thrombosis in spontaneous intracranial hypotension: hypotheses on possible mechanisms. J Neurol 2006;253:1197-1202 CrossRef Medline

71. Richard S, Kremer S, Lacour JC, et al. Cerebral venous thrombosis caused by spontaneous intracranial hypotension: two cases. Eur J Neurol 2007;14:1296-98 CrossRef Medline
72. Berroir S, Grabli D, Heran F, et al. Cerebral sinus venous thrombosis in two patients with spontaneous intracranial hypotension. Cerebrovasc Dis 2004;17:9-12 CrossRef Medline

73. Neary D, Snowden JS, Gustafson L, et al. Frontotemporal lobar degeneration: a consensus on clinical diagnostic criteria. Neurology 1998;51:1546-54 CrossRef Medline

74. Neary D, Snowden JS, Northen B, et al. Dementia of frontal lobe type. J Neurol Neurosurg Psychiatry 1988;51:353-61 CrossRef Medline

75. Hong M, Shah GV, Adams KM, et al. Spontaneous intracranial hypotension causing reversible frontotemporal dementia. Neurology 2002;58:1285-87 CrossRef Medline

76. Mostofi E, Schievink WI, Sim VL. Dural reduction surgery: a treatment option for frontotemporal brain sagging syndrome. Can J Neurol Sci 2016;43:593-95 CrossRef Medline

77. Wicklund MR, Mokri B, Drubach DA, et al. Frontotemporal brain sagging syndrome: an SIH-like presentation mimicking FTD. Neurology 2011;76:1377-82 CrossRef Medline

78. Schievink WI, Maya MM, Barnard ZR, et al. Behavioral variant frontotemporal dementia as a serious complication of spontaneous intracranial hypotension. Oper Neurosurg (Hagerstown) 2018;15:50515 CrossRef Medline

79. Firat AK, Karakas HM, Firat Y, et al. Spontaneous intracranial hypotension with pituitary adenoma. J Headache Pain 2006;7:47-50 CrossRef Medline

80. Tapia DQ, Pardo J, Serrano JM, et al. Spontaneous intracranial hypotension: use of unenhanced MRI. Neuroradiology 2000;42:529-31 CrossRef Medline

81. Tsui EY, Ng SH, Cheung YK, et al. Spontaneous intracranial hypotension with diffuse dural enhancement of the spinal canal and transient enlargement of the pituitary gland. Eur J Radiol 2001;38:59-63 CrossRef Medline

82. Leung GK, Ho J, Pu JK. Pituitary enlargement in spontaneous intracranial hypotension: a diagnostic pitfall. Acta Neurochir (Wien) 2011;153:2445-46 CrossRef Medline

83. Luna J, Khanna I, Cook FJ, et al. Sagging brain masquerading as a pituitary adenoma. J Clin Endocrinol Metab 2014;99:3043-43 CrossRef Medline

84. Fearnley JM, Stevens JM, Rudge P. Superficial siderosis of the central nervous system. Brain 1995;118(Pt 4):1051-66 CrossRef Medline

85. Levy M, Turtzo C, Llinas RH. Superficial siderosis: a case report and review of the literature. Nat Clin Pract Neurol 2007;3:54-58 CrossRef Medline

86. Linn J, Herms J, Dichgans M, et al. Subarachnoid hemosiderosis and superficial cortical hemosiderosis in cerebral amyloid angiopathy. AJNR Am J Neuroradiol 2008;29:184-86 CrossRef Medline

87. Beck J, Häni L, Ulrich CT, et al. Diagnostic challenges and therapeutic possibilities in spontaneous intracranial hypotension. Clinical and Translational Neuroscience 2018;2:2514183X1878737 CrossRef

88. Webb AJ, Flossmann E, Armstrong RJ. Superficial siderosis following spontaneous intracranial hypotension. Pract Neurol 2015;15:382-84 CrossRef Medline

89. Schievink WI, Maya MM. Spinal meningeal diverticula, spontaneous intracranial hypotension, and superficial siderosis. Neurology 2017;88:916-17 CrossRef Medline

90. Kumar N. Neuroimaging in superficial siderosis: an in-depth look. AJNR Am J Neuroradiol 2010;31:5-14 CrossRef Medline

91. Kumar N, Lane JI, Piepgras DG. Superficial siderosis: sealing the defect. Neurology 2009;72:671-73 CrossRef Medline

92. Kumar N, McKeon A, Rabinstein AA, et al. Superficial siderosis and CSF hypovolemia: the defect (dural) in the link. Neurology 2007; 69:925-26 CrossRef Medline

93. Schievink WI, Wasserstein P, Maya MM. Intraspinal hemorrhage in spontaneous intracranial hypotension: link to superficial siderosis? Report of 2 cases. J Neurosurg Spine 2016;24:454-56 CrossRef Medline 